\title{
Desain Jaringan Sensor Nirkabel Untuk Pemantauan Suhu Dan Kelembaban Lingkungan Berbasis SMS
}

Kostan D. F. Mataubenu ${ }^{\mathrm{a}}$, Muhammad Miftahul Munir ${ }^{\mathbf{b}}$

${ }^{a}$ Program ${ }^{a}$ Program Studi Pendidikan Fisika, Sekolah Tinggi Keguruan dan Ilmu Pendidikan,Soe, TTS - NTT, Indonesia, email: fajarlon@gmail.com ${ }^{b}$ Fakultas MIPA, InstititutTeknologi Bandung,Bandung,Jawa Barat, Indonesia, email: miftah@ fi.itb.ac.id

\section{Article Info}

\section{Article history:}

Received 16 Desember 2018

Received in revised form 11 April 2019

Accepted 20 April 2019

\section{$\mathrm{DO}$}

https://doi.org/10.32938/slk.v2i1.665

\section{Keywords:}

GSM900

Jaringan sensor nirkabel

SHT10

Xbee

\section{Pendahuluan}

Perkembangan penelitian terkini tentang jaringan sensor nirkabe khususnya dalam pemantauan iklim, telah diaplikasikan pada bidang pertanian dan peternakan seperti proyek green house, pengontrolan kesuburan tanah, pabrik penetasan telur pada peternakan unggas dan sebagainya (Wang, Zhang, \& Wang, 2006)

Tujuan penggunaan jaringan sensor nirkabel adalah untuk mengatasi kendala-kendala yang terjadi di lapangan dalam pengukuran, pemantauan dan pengontrolan suatu sistem (Baronti, Prashant, Chook, Chessa, Gotta, \& Fun Hu 2007). Jaringan sensor nirkabel dapat meningkatkan resolusi pengukuran ataupun mengendalikan suatu besaran fisis secara masal karena banyak node sensor yang disebar. Selain itu, karena berkomunikasi secara nirkabel, memungkinkan untuk diaplikaskan pada daerah yang sulit dijangkau secara luas (Akyildiz, Su, Sankarasubramaniam, \& Cayirci, 2002). Dengan menggunakan jaringan sensor nirkabel, seorang peneliti atau pengontrol tidak perlu terjun langsung ke lapangan, tetapi dapat mengakses atau mengontrol sistem dari jauh menggunakan laptop, remote control dan sebagainya. Jaringan sensor nirkabe sangat bermanfaat jika diaplikasikan pada sistem yang membutuhkan banyak sensor seperti pemantauan kekuatan jembatan, pemantauan iklim dalam sebuah sistem, gunung api dan sebagainya (Akyildiz, Su, Sankarasubramaniam, \& Cayirci, 2002).

Salah satu protokol yang digunakan dalam komunikasi jaringan senso nirkabel adalah protokol ZigBee yang menggunakan gelombang radio frekuensi 2,4 GHz dan merupakan salah satu jenis Wireless Personal Area Network (WPAN) berstandar IEE802.15.4. Salah satu device yang dapat digunakan untuk aplikasi ZigBee dalam jaringan sensor nirkabel adalah Xbee. Xbee merupakan sebuah modul RF berstandar IEE 802.15.4 dengan frekuensi 2,4 GHz yang murah dan low power (Ruiz-Garcia, Barreiro, \& Robla, 2008). XBee Pro dapa melakukan pengiriman data pada jarak paling jauh dalam ruangan adalah $90 \mathrm{~m}$ dan di ruang terbuka mendekati 1,5 km. Tegangan kerja XBee adalah 3,3 V dan dapat dikonfigurasi untuk berkomunikasi secara point to multipoint, broadcast, peer to peer memungkinkan untuk digunakan dalam aplikasi WSN (Keshtgari \& Deljoo, 2012; Flaudi, 2010)

Sebagai contoh penerapan Xbee, Liu \& Liu (2013), merancang sebuah jaringan sensor nirkabel untuk aplikasi pemantauan keadaan lingkungan sebuah pabrik penetasan. Sistem dibuat dengan menggunakan protokol ZigBee yang mana data hasil pemantauan dikirimkan ke pusat pemantauan atau koordinato dimana software akuisisi datanya dibuat dengan menggunakan program Visual Basic.

Secara umum, data hasil pengukuran jaringan sensor nirkabel yang diterima oleh koordinator ditampilkan secara lokal pada koordinator yang dihubungkan dengan komputer. Hal ini menyebabkan data tidak dapat diakses secara luas. Dalam beberapa kasus, kebebasan akses informasi data hasil pemantauan dengan jaringan sensor nirkabel sangat diperlukan. Oleh karena itu sangat penting untuk dirancang sebuah sistem jaringan sensor nirkabel yang data-data hasi pengukurannya dapat diakses secara bebas tanpa bergantung pada tempat dan waktu.

Berdasarkan hal tersebut, maka dalam penelitian ini dikembangkan sistem pemantauan berdasarkan jaringan sensor nirkabel yang dikoneksikan ke jaringan short message system (SMS). Sistem jaringan sensor nirkabel ini diaplikasikan pada pemantauan suhu dan kelembaban. Jaringan sensor nirkabel yang dibangun menggunakan protokol Zigbee dengan memanfaatkan modul Xbee Pro. Data hasil pemantauan dikirimkan melalui GPRS (General Packet Radio Service) dan diterima oleh nomor HandPhone tujuan.

\section{Metode}

Metode yang digunakan dalam penelitian ini adalah eksperimen perancangan dan pengujian jaringan sensor nirkabel berbasis sms. Sistem terdiri dari perangkat keras dan perangkat lunak. Perangkat keras terdiri dari dua bagian besar yaitu bagian yaitu end device dan center device. End device terdiri dari 3 komponen utama yaitu sensor SHT (sensor suhu dan kelembaban), mikrokontroler ATMega8535, dan XBee Pro yang akan diatur sebagai pemancar, sedangkan center device terdiri dari Xbee Pro yang berfungsi sebagai penerima dan modul SIM900 untuk keperluan SMS

Eksperimen ini menggunakan 3 buah end device 1 buah center device. Oleh karena modul RF XBee Pro yang digunakan berasal dari series 1 maka eksperimen ini dikembangkan dalam topologi star (Munir, Mataubenu, Salam, Latief, \& Khairurrijal, 2015), sebagaimana ditunjukkan pada Gambar 1.

Perangkat lunak berupa bahasa C, AT Command dan XCTU. Bahasa C digunakan untuk memprogram mikrokontroler ATMega8535, AT Command digunakan untuk keperluan SIM900 mengirimkan SMS dan XCTU digunakan untuk mengatur XBee Pro agar dapat berkomunikasi satu dengan yang lainnya. Bahasa $\mathrm{C}$ yang dibuat berguna untuk membaca sensor SHT dan mengirimkannya ke center device secara nirkabel melalui XBee Pro. AT Command disisipkan dalam data yang dikirim dari end device diterima oleh SIM900 melalui XBee Pro. AT Command berupa perintah kepada SIM900 untuk meneruskan data hasil bacaan suhu dan kelembaban dalam bentuk SMS.

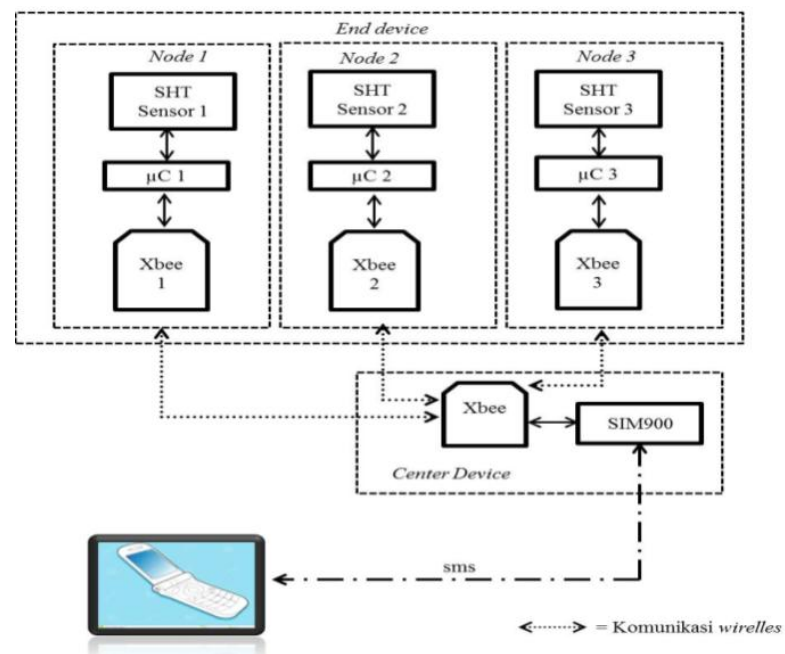

Gambar 1. Desain perngkat keras jaringan sensor nirkabe

Pengujian dilakukan terhadap sistem berupa uji bacaan sensor, kalibrasi sensor, uji pengiriman data dari end device ke center device dan uji pengiriman data dari end device ke ke nomor HandPhone penerima. Untuk keperluan pengujian maka dibuat perangkat komunikasi serial dan interface menggunakan Delphi 7 untuk menampilkan data yang diterima oleh center device di komputer

\section{Hasil dan Pembahasan}

\subsection{Perangkat Keras}

End device sebagaimana disebutkan di atas terdiri dari sensor SHT, mikrokontroler ATMega8535 dan modul Xbee Pro. Sensor SHT merupakan sensor suhu dan kelembaban yang outputnya sudah dalam bentuk digital. Akses 
terhadap sensor SHT dilakukan melalui komunikasi 2-wire (Sensor SHTxx datasheet, 2014) sehingga hanya membutuhkan dua buah kabel koneksi saja antara sensor SHT (clock dan data) dan mikrokontroler ATMega8535 (pin $\mathrm{A}_{0}$ dan $\mathrm{A}_{1}$ ). Komunikasi antara mikrokontroler ATMega8535 dan modul RF XBee Pro dalam bentuk serial sehingga dikoneksikan oleh dua buah pin (untuk transmitter dan receiver). Koneksi antar komponen end device melalui pin-pin sebagaimana ditunjukkan pada Gambar 2 berikut ini.

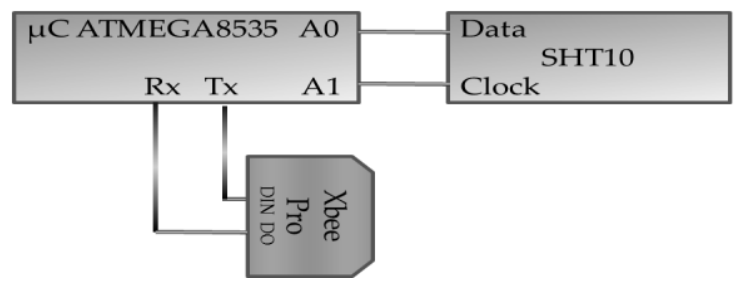

Gambar 2. Koneksi antara ATMega8535, XBee Pro dan SHT

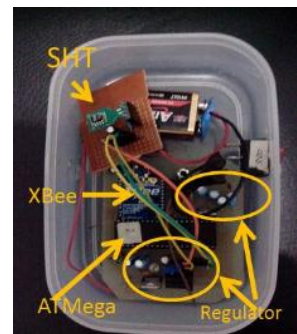

Gambar 3. Hasil rancangan end device

Konsumsi tegangan mikrokontroler ATMEGA8535, SIM900 dan sensor SHT10 adalah 5V DC sedangkan modul RF Xbee Pro adalah 3,3V DC sehingga dibuat rangkaian regulator tegangan dengan menggunakan IC LM7805 (5 V) dan $\operatorname{LM} 317(3,3 \mathrm{~V})$.

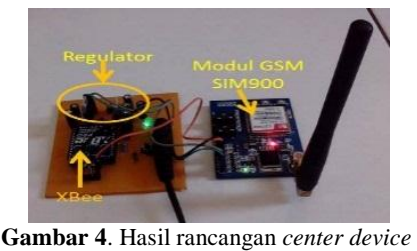

\subsection{Perangkat Lunak}

\subsubsection{Program Mikrokontroler}

Program pada mikrokontroler dirancang dengan menggunakan Bahasa C. Program diatur untuk membaca temperatur dan kelembaban dari sensor SHT10 kemudian mengirimkannya ke modul Xbee Pro secara serial untuk selanjutnya dikirimkan ke penerima melalui gelombang radio. Pembacaan data sensor oleh mikrokontroler dilakukan dengan komunikasi 2-wire. Karena output sensor sudah dalam nilai digital terkalibrasi, maka program pada mikrokontroler diatur untuk menghasilkan clock ke pin serial clock sensor (Andrinato, 2013) dan salah satu pin diatur untuk menerima data dari pin data SHT10. Data yang dibaca oleh mikrokontroler kemudian dikirimkan secara serial ke modul RF Xbee Pro untuk dikirimkan secara nirkabel ke penerima di center device. Selain itu, program dibuat untuk mengirimkan AT Command ke penerima, yaitu perintah ke modul GSM SIM900 (Mouly \& Pauted, 1997) agar data-data tersebut dikirimkan melalui SMS setelah diterima oleh receiver. Program pada masing-masing mikrokontroler pada setiap end device diatur dengan delay yang bebeda-beda dengan maksud agar data-data tesebut tidak saling bertabrakan sehingga menimbulkan kesalahan pembacaan.

\subsubsection{Konfigurasi RF Modul XBee Pro}

Karena modul XBee Pro yang digunakan adalah series 1 maka konfigurasi hanya dapat dilakukan dalam bentuk topologi star dengan transparent mode. Konfigurasi dilakukan bertujuan untuk mengatur komunikasi di antara modul yang digunakan. Konfigurasi dilakukan dengan menggunakan software X-CTU dari Digi International. Modul RF Xbee Pro dihubungkan secara serial dengan komputer kemudian diisi nilai-nilai register yang berperan penting dalam protokol komunikasi yang dibangun. Register yang perlu diatur dengan software $\mathrm{X}$-CTU adalah CH (channel), PAN ID (personal area network ID), DL (destination address low). Hanya modul dengan nilai $\mathrm{CH}$ dan PAN ID yang sama yang dapat melakukan komunikasi baik itu sebagai transmitter maupun receiver. Konfigurasi dilakukan dengan menggunakan perintah AT command pada tab Terminal software X-CTU (Flaudi, 2010).
3.3 Pengujian Sistem dan Analisis Data

\subsubsection{Uji Komunikasi TransmitterDan Receiver}

Tabel 1. Nilai konfigurasi modul RF XBee Pro

\begin{tabular}{|c|c|c|c|c|}
\hline \multirow[b]{2}{*}{ Register } & \multicolumn{4}{|c|}{ NILAI YANG DIBERIKAN } \\
\hline & Receiver & Transmitter1 & $\begin{array}{l}\text { Transmitte } \\
\text { r2 }\end{array}$ & Transmitter 3 \\
\hline $\mathrm{CH}$ (channel) & $0 \mathrm{x} 0 \mathrm{~F}$ & 0x0F & $0 \mathrm{x} 0 \mathrm{~F}$ & $0 \mathrm{x} 0 \mathrm{~F}$ \\
\hline $\begin{array}{l}\text { PAN ID } \\
\text { (personal area } \\
\text { network) } \\
\text { DH (destination } \\
\text { address high) }\end{array}$ & $0 \times 5241$ & $0 \times 5241$ & $0 \times 5241$ & $0 \times 5241$ \\
\hline $\begin{array}{l}\mathrm{DL} \text { (destination } \\
\text { address low) }\end{array}$ & 0xFFFF & 0xFF01 & 0xFF01 & 0xFF01 \\
\hline $\begin{array}{l}\text { MY (Address) } \\
\mathrm{CE}(\text { coordinator } \\
\text { enable })\end{array}$ & 0xFF01 & 0xFF02 & 0xFF03 & 0xFF04 \\
\hline
\end{tabular}

Hal pertama yang harus dilakukan sebelum menguji komunikasi antara transmitter dan receiver adalah melakukan konfigurasi pada XBee Pro. Adapun nilai-nilai register yang diisi dengan bilangan heksa sebagaimana terlihat pada Tabel 1.

Dari Tabel 1 terlihat bahwa nilai $\mathrm{CH}$ dan PAN ID sama untuk semua modul XBee Pro. Hal ini menunjukkan bahwa baik transmitter maupun receiver memiliki alamat saluran dan jaringan yang sama sehingga dapat saling berkomunikasi. Pada DH masing-masing modul Xbee Pro diset 0x00 yang sebenarnya merupakan bagian dari konfigurasi topologi star. DL pada receiver diisi dengan 0xFFFF yang menandakan bahwa sistem jaringan sensor akan bekerja dengan sistem topologi star. Dengan pengaturan seperti ini, receiver bisa berkomunikasi dengan semua transmitter yang memiliki nilai $\mathrm{CH}$ dan PANID yang sama dengan receiver Artinya data yang dikirimkan oleh receiver akan diterima oleh transmitter yang mempunyai nilai $\mathrm{CH}$ dan PANID yang sama dengan receiver. Berbeda dengan receiver, DL pada semua transmitter diberikan 0xFF01 yang tidak lain adalah nilai dari MY atau alamat modul XBee Pro receiver. Ini dilakukan agar transmitter bisa melakukan pengiriman data ke receiver. $\mathrm{CE}$ bernilai $0 \mathrm{x} 01$ untuk receiver yang berarti mengaktifkan modul $\mathrm{RF}$ Xbee Pro sebagai coordinator sedangkan pada transmitter diberikan nilai 0x00 yang mengindikasikan modul RF Xbee Pro diatur sebagai end device.

Setelah konfigurasi, maka komunikasi antara end device dengan center device dapat diuji. Untuk keperluan pengujian, maka didesain komunikasi serial RS232 dan penampil data di komputer menggunakan Delphi 7.0. Sistem dikoneksikan dengan center device sehingga menampilkan data-data yang diterima.

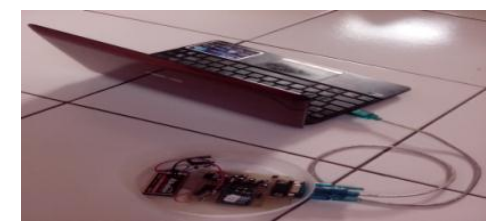

Gambar 5. Koneksi center device dengan komputer melalui rangkaian RS232

Dengan demikian data-data yang dikirimkan oleh end device diterima oleh center device kemudian diteruskan ke komputer dan ditampilkan menggunakan bantuan Delphi 7.0 seperti Gambar 6. Hasil uji menunjukkan bahwa komunikasi antara end device dengan center device berjalan baik.

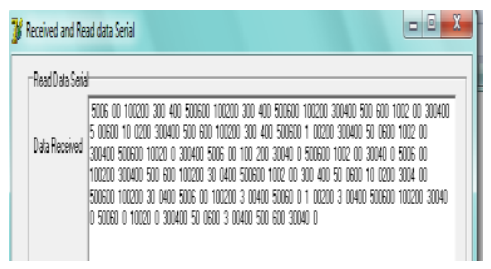

Gambar 6. Data yang dikirimkan oleh 3 buah end device

\subsubsection{Uji Jarak Maksimum Antara End Device dan Center Device}

Pada pengujian ini dikirimkan 1500 karakter dari pengirim ke penerima. Pengujian dilakukan di tempat terbuka dengan asumsi hambatan yang sangat kecil. Dari pengujian yang dilakukan didapati bahwa semakin besar peluang data akan hilang ketika jarak antara penerima dan pengirim semakin besar. Hal ini 
diakibatkan oleh sinyal yang semakin melemah seiring dengan pertambahan jarak antara pengirim dan penerima.

Untuk lebih jelas hasil pengujian dapat dilihat pada Grafik pada Gambar 7 berikut ini. Pengujian dilakukan pada modul Xbee Pro $1 \mathrm{~mW}$ (jangkauan maksimum $100 \mathrm{~m}$ ). Dari Grafik di atas terlihat bahwa jumlah data yang hilang terhadap jarak terjadi ketika penerima dan pengirim berada pada jarak lebih besar dari $75 \mathrm{~m}$, sedangkan data tidak diterima pada jarak pisah $90 \mathrm{~m}$. Hal ini terjadi karena data yang dikirimkan dalam jumlah yang banyak, sedangkan sinyal semakin melemah. Namun pada bagian pengujian dengan data pengiriman yang sedikit didapati bahwa data masih bisa diterima sampai pada jarak $95 \mathrm{~m}$.

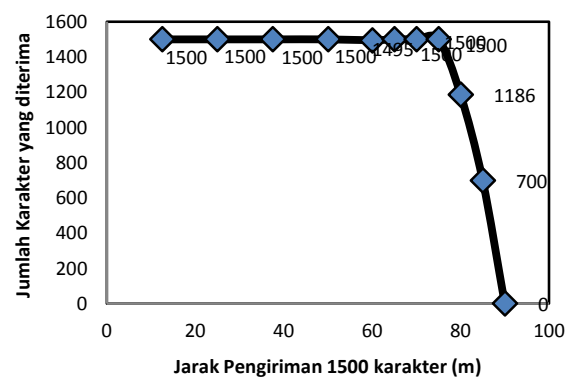

Gambar 7. Grafik hubungan antara jumlah data yang diterima oleh center device dan jarak antara end device dan center device

\subsubsection{Uji sensor SHT10}

Sensor SHT10 merupakan sensor yang digunakan untuk mengukur temperatur dan kelembaban. Output sensor adalah berbentuk digital dan sudah terkalibrasi dengan akurasi pengukuran untuk kelembababan adalah +/-3\% RH (kelembaban nisbi) dan $+/-0,4^{\circ} \mathrm{C}$ untuk temperature (Sensor SHTxx datasheet, 2014). Mikrokontroler ATMEGA8535 digunakan untuk membaca data suhu dan kelembaban dan mengirimkannya secara nirkabel ke penerima untuk ditampilkan di komputer.

Data yang dibaca oleh mikrokontroler dikirimkan ke penerima kemudian pada penerima dipisahkan secara tepat oleh program yang dibuat dengan menggunakan Delphi 7. Data tersebut dikonversi untuk menjadi data suhu maupun kelembaban terukur melalui persamaan kalibrasi bawaan.

\subsubsection{Pengujian Sistem Secara Menyeluruh}

Setelah langkah-langkah di atas dilakukan, maka sistem siap diuji secara keseluruhan. Pengujian yang dilakukan adalah menguji pengiriman data suhu dan kelembaban dari tiga transmitterr ke receiver dan pengujian selanjutnya adalah uji pengiriman data melalui SMS.

\subsubsection{Uji Pengirman Data Suhu dan Kelembaban Dari End Device ke Center Device}

Hal ini dilakukan untuk melihat apakah receiver dapat menerima data suhu dan kelembaban yang dikirimkan oleh 3 end device berhasil. Pengujian dilakukan dengan mengirimkan data suhu dan kelembaban ke center device yang dihubungkan dengan komputer melalui rangkaian RS232. Software akuisisi data dibuat dengan menggunakan Delphi 7.0 yang dilengkapi dengan database. Dari pengujian yang dilakukan didapati bahwa center device mampu menerima semua data suhu dan kelembaban yang dikirimkan oleh end device. Sistem akuisisi data yang dibuat seperti pada Gambar 8.

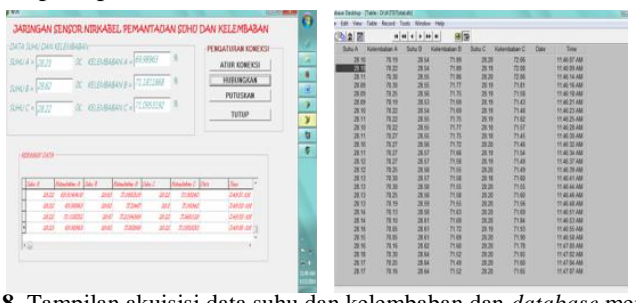

Gambar 8. Tampilan akuisisi data suhu dan kelembaban dan database menggunakan Delphi 7.0

Data suhu dan kelembaban yang dikirimkan oleh end device ke center device terekam dalam database, kemudian digrafikkan terhadap waktu. Hasilnya akan seperti pada Gambar 9 dan Gambar 10. Dari Grafik pada Gambar 9 dan Gambar 10 dapat dilihat bahwa semakin besar suhu maka kelembabannya semakin rendah. Pengukuran dilakukan pada siang hari di Kampus ITB bandung sehingga terlihat rata-rata suhu $28^{\circ} \mathrm{C}$ sampai $30^{\circ} \mathrm{C}$. Sedangkan kelembaban berkisar antara $64 \%-72 \%$

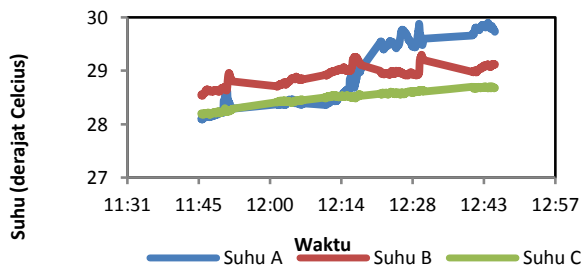

Gambar 9. Grafik suhu terhadap waktu hasil pengukuran dengan jaringan sensor nirkabel yang diterima oleh komputer

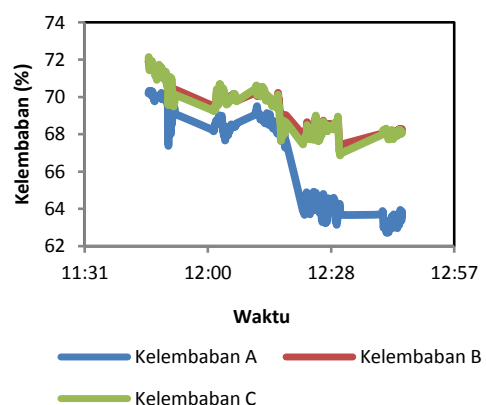

Gambar 10. Grafik kelembaban terhadap waktu hasil pengukuran dengan jaringan sensor nirkabel yang diterima oleh komputer

\subsubsection{Pengujian Pengiriman Data Melalui SMS}

Pengujian pengiriman data melalui sms dilakukan dengan megirimkan data yang dikirimkan oleh setiap end device ke hand phone penerima. Pengujian dilakukan dengan membandingkan data yang diterima oleh komputer dan data yang diterima oleh handphone penerima. Sebelum melakukan pengujian, dimodifikasi perangkat keras dengan cara menghubungkan center device (terdiri dari modul RF Xbee Pro dan Modul GSM SIM900) dan rangkaian RS232 dengan komputer. Data yang dikirimkan melalui sms akan diterima juga pada komputer. Dari hasil pengujian yang dilakukan didapati bahwa data yang diterima oleh komputer sama dengan data yang diterima oleh handphone penerima. Dapat disimpulkan bahwa sepanjang tidak terjadi kehilangan data pada proses pengiriman dari end device ke center device, maka data tersebut akan diteruskan secara utuh ke handphone penerima.

Pengiriman data untuk masing-masing end device dilakukan dengan delay pengiriman yang berbeda-beda. Hal ini dilakukan agar data dari setiap end device dapat dikirimkan secara tepat oleh modul GSM SIM900 ke penerima. Gambar 11 menunjukkan data yang diterima oleh handphone yang berisi nomor penerima.

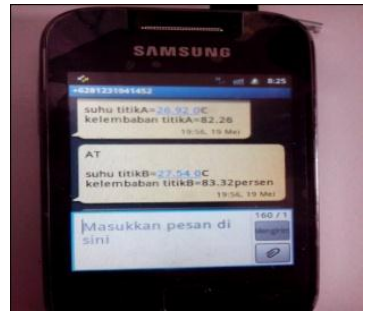

Gambar 11. Pesan suhu dan kelembaban yang diterima

\section{Simpulan}

Telah dirancang sebuah sistem jaringan sensor nirkabel untuk aplikasi pemantauan suhu dan kelembaban dengan topologi star yang terdiri dari 3 buah transmitter dan satu receiver. Variabel fisis yang dipantau masih terbatas pada suhu dan kelembaban dengan menggunakan sensor SHT10. Pengiriman data dilakukan secara nirkabel dengan menggunakan Modul RF XBee Pro series 1. Jarak maksimum pengiriman data (jumlah data yang kecil) dari pengirim ke penerima di tempat terbuka untuk XBee Pro $1 \mathrm{~mW}$ adalah $95 \mathrm{~m}$. Hasil pengukuran suhu dan kelembaban yang dikirimkan ke penerima diteruskan melalui sms menggunakan modul GSM SIM900 ke penerima. Sistem telah diuji dan bekerja dengan baik.

\section{Pustaka}

Akyildiz, F., Su, W., Sankarasubramaniam, Y., \& Cayirci, E. (2002). Wireless sensor networks: a survey. Computer Networks, 38, 393-422. (www.ee.oulu.fi/ carlos/WSNPapers/AK02.pdf)

Andrinato, H. (2013). Pemrograman mikrokontroler AVR ATmegal6 menggunakan Bahasa C (codeVision avr). Bandung: Informatika.

Baronti, P., Prashant, P., Chook, V., Chessa, S., Gotta, A., \& Fun Hu, Y. (2007) Wireless sensor networks:: a survey on the state of the art and the ZigBee standards. Computer Communications, 30, 16551695.)(citeseerx.ist.psu.edu/viewdoc/download?doi=10.1.1.467..).

Flaudi, R. (2010). Bulding Wireless Sensor Network. USA: O'Reilly Media, Inc.,.

Keshtgari, M., \& Deljoo, A. (2012). A Wireless Sensor Network Solution for Precision Agriculture Based on ZigBee Technology. Wireless Sensor Network 5 , 25-30. (https://www.researchgate.net/publication/228517328_A_Wireless Sensor_Network_Solution_for_Precision_Agriculture_Based_on_Zi gBee_Technology) 
Liu, Z., \& Liu, H. (2013). Design of Environment Monitoring System in Hatcheries Based on WSN. Sensors \& Transducers, 158, 153-158.

Mouly, M., \& Pauted, M. (1997). The GSM System for Mobile Communications. France: F-91120 Plaiseau

Munir, M. M., Mataubenu, K. D., Salam, R. A., Latief, H., \& Khairurrijal. (2015). Development of a Wireless Sensor Network for Temperature and Humidity Monitoring. Applied Mechanics and Materials, 771, 4245.(https://www.scientific.net/AMM.771.42)

Ruiz-Garcia, L., Barreiro, P., \& Robla, J. (2008). Performance of ZigBee-Based wireless sensor nodes for real-time monitoring of fruit logistics. Food Engineering, 87 , $405-415$
Sensor SHTxx datasheet. (2014, April 25). Retrieved from http://www.seserion.com

Wang, N., Zhang, N., \& Wang, M. (2006). Wireless sensors in agriculture and food industry - recent development and future perspective. Computer and Electronics in Agriculture, 50, 1-14. (https://www.sciencedirect.com/science/article/pii/S0168169905001 572)

(https://www.sciencedirect.com/science/.../S0260877408000125) 